\title{
VIII.
}

\section{Über einen Fall von mittelst Wasserstoffsuperoxyd aus dem Ohre herausgetriebenen Fremdkörper.}

\author{
Von \\ Dr. Heinrich Halász, \\ Spitalsordinarius in Miskolcz (Ungarn).
}

Für die Entfernung ins Ohr geratener Fremdkörper sind verschiedene Verfahren in Anwendung. Als mildestes Verfahren in erster Reihe die Ausspritzung mit Wasser, nur wenn dieses im Stiche ließe, greifen wir zur instrumentellen Entfernung, in oder ohne Narkose, je nachdem wir es mit einem geduldigen oder sehr empfindlichen Patienten zu tun haben. In dem weiter unten mitzuteilenden Falle, wo ich trotz mehrere Tage hindurch versuchter Ausspritzungsversuche nicht zum Resultat gelangte, war schon alles für die Narkose vorbereitet, um die Bohne auf instrumentellem Wege zu entfernen, da das ungeberdige, empfindliche und durch schon außerhalb des Spitals vorgenommene Extraktionsversuche gequälte und ersehreckte Kind niemanden mehr in die Nähe des Ohres zulieb, - als ich am Morgen des Operationstages den Fremdkörper an dem in die Öffnung des Gehörganges eingelegten Wattetampon haftend fand. Der Fall war folgender :

D. R., 4 Jabre alter Knabe, bat sich 1-2 Wochen vor der Spitalsaufnahme eine Bohne ins Ohr gesteckt. Der Vater erfuhr es jedoch erst vor zwei Tagen. Der dortige Arzt hat mehrfache erfolglose Extraktionsversuche unternommen. Die Inspektion ergab Eiterausflu $\beta$ aus dem linken Obre. Verschluß des Gehörganges durch Granulationen bis auf einen Spalt ron $1-2 \mathrm{~mm}$, ein Einblick selbst nach erfolgter Ausspritzung unmöglich. Der kleine Patient war fieberfrei, klagte über keine Schmerzen, so daß ein Zuwarten statthaft erschien, ich verordnete Eisbeutel aufs $\mathrm{Ohr}$ und gegen die Eiterung Instillationen von (10proz.) Hydrogenhyperoxyd in den Gehörgang. Drei Tage hintereinander versuchte ich jeden Morgen unter gleichzeitiger Kauterisation der Granulationen (mit Trichloressigsäure) die angeblich hereingeratene Bohne mittelst $4-5$ Wassereinspritzungen zu entfernen. Doch vergebens. Am Morgen des 4. Tages waren die Granulationen bereits in dem Maße verkleinert, daß durch den eingeführten kleinkalibrigen Ohrenspiegel ein gelblichweißer, rundlicher Körper in der Tiefe zwischen 
die Gehörgangswände eingekeilt, sichtbar wurde. Da das reizbare Kind keinen instrumentellen Eingriff gestattete, griff ich abermals zur Spritze, obne jedoch den Fremdkörper von der Stelle bringen zu können. Ich wiederbolte meine bisherigen Anordnungen, mit dem Vorsatze, falls die Einspritzungen auch am nächsten Morgen resultatlos wăren, die Extraktion in der Narkose vorzunehmen. Wie überrascht war ich, als ich am Morgen des 5. Tages die weißlichgelbe, an einem Pole einen kleinen Defekt anfweisende Bohne an dem in die Obröffnung eingelegten Wattetampon klebend, fand. Die Rotekrenzwärterin gab an, daß der Fremdkörper vor ibren Augen durch die nach der am selben Morgen erfolgten Eingießung des Wasserstoffsuperoxyds aufgetretenen Blasenbildung durch die vordringenden Blasen herausgeschleudert wurde. Um nun den Fremdkörper bis zu meiner Ankunft an Ort und Stelle zu fixieren, gab sie den Wattetampon in die augere öfinung des Obres.

Der Mechanismus der Herausbeförderung der Bohne lälit sich nur aus Verdrängung derselben durch die Blasenbildung erklären. Die Erweiterung des Gehörganges beziehungsweise der äußeren Ohröffnung zufolge Verkleinerung der Granulationen kommt als wesentliches Hilfsmoment in Betracht.

Wer je Gelegenheit hatte, zu sehen, welohe Eiterbröckeln durch die nach WasserstoffsuperoxydeingieBungen auftretende Blasenbildung aus der Tiefe des Gehörgangs, der Trommelhöhle an die Oberfläche befördert werden, der wird keinen Moment an einer analogen Wirkung, wie sie in unserem Falle vorlag, zweifeln.

Auf Grund dieser Erfahrung halte ich es am Platze, bei Fremdkörpern eine 5-10 proz. Wasserstoffsuperoxydlösung in den Gebörgang zu gießen, besonders in jenen Fällen, wo die Spritzungen zu keinem Resultat geführt haben und der Arzt nicht gentugende Übung für die Vornahme eines instrumentellen Eingriffes besitzt.

Im Jahre 1897 habe ich das Wasserstoffsuperoxyd wegen seiner blutstillenden und sekretionsbeschränkenden Wirkung bewährtes Mittel in der Nasen- und Ohrenheilkunde anfs wärmste empfohlen; der Zufall fübrte mich darauf, eine neve Eigenschaft des Mittels zu entdecken, welehe eine weitere ausgedehntere Verwendung desselben empfehlenswert erscheinen läßt. 